\title{
IVAIRAUS MEISTRIŠKUMO IR AMŽIAUS KREPŠININKIŲ FIZINIO IŠSIVYSTYMO, FIZINIŲ GALIŲ BEI FUNKCINIŲ RODIKLIŲ LYGINAMOJI ANALIZE்
}

\author{
Rūtenis Paulauskas, Juozas Skernevičius, Rasa Paulauskienė \\ Vilniaus pedagoginis universitetas, Vilnius, Lietuva
}

Rūtenis Paulauskas. Biomedicinos mokslų daktaras. Vilniaus pedagoginio universiteto Sporto metodikos katedros docentas. Mokslinių tyrimu kryptis — didelio meistriškumo sportininkų rengimo valdymas.

\section{SANTRAUKA}

Tikslas — nustatyti 16 metu ir didelio meistriškumo krepšininkiu fizin̨ išsivystyma, fizinị bei funkcini pajèguma, atlikti rodikliu lyginamaja analizę.

Tyrimo metu nustatème: ūgi, kūno masę, kūno masès indeksa (KMI), plaštaku statinę jèga, gyvybini plaučiu tūri $(G P T)$, riebalu ir raumenu masę bei ju indeksq (RRMI). Tirdami fizines ir funkcines galias nustateme: vienkartini raumenu susitraukimo galinguma (VRSG), anaerobini alaktatini raumenu galinguma (AARG), 30 s darbo veloergometru mišru anaerobini alaktatini-glikolitini raumenu galinguma (AAGRG). Vikruma tyrème „Šešiakampio“ testu. Tiriant psichomotorines funkcijas nustatytas psichomotorinès reakcijos laikas (PRL) ir judesiu dažnis (JD) per 10 s. Kraujotakos ir kvépavimo sistemu funkcinis pajégumas vertintas pagal Rufje indeksq.

Tyrimo rezultatai apdoroti matematinès statistikos metodais: apskaičiuotas aritmetinis vidurkis $(\bar{x})$ ir reprezentacine paklaida $(S \bar{x})$, standartinis nuokrypis $(S)$. Taip pat pateikti didžiausias ir mažiausias rodikliai. Apskaičiuotas aritmetiniu vidurkiu skirtumo patikimumas taikant dispersinès analizès metoda ir nustatant F kriteriju. Norint vaizdžiai palyginti atskiru žaidèju ir grupiu ¿vairius rodiklius, duomenys standartizuoti ir sudaryti normalizuotu rodikliu profiliai.

Tyrimas parodè, kad jau 16 metu krepšininkès savo ügiu ir kūno mase nesiskiria nuo didelio meistriškumo komandos žaidèju. Visgi jos atsilieka plaštaku jèga ir turi didesnę kūno riebalu masę.

Santykinis VRSG rodiklis suaugusiu žaidèju yra kur kas didesnis negu jaunu krepšininkiu. Suaugusiuju AARG bei AAGRG rodikliai taip pat buvo geresni nei jaunu krepšininkiu, tačiau vikrumas abieju grupiu skyrèsi nepatikimai.

Psichomotorinès reakcijos laiko rodikliai tarp grupiu reikšmingai nesiskyrè, tačiau judesiu dažnis didelio meistriškumo žaidèju buvo didesnis.

Abieju grupiu žaidëju kraujotakos ir kvépavimo sistemu funkciniai rodikliai geri. Jaunu krepšininkiu Rufje indekso rodikliai patikimai nesiskyre nuo suaugusiuju.

Rezultatyviausia didelio meistriškumo komandos žaidëja didesnio nei kitos fizinio ir funkcinio pajegumo, jos VRSG ir AARG rodikliai ypač geri.

Raktažodžiai: moteru krepšinis, fizinis pajègumas, galingumas, raumenu masè, jèga, funkcinis pajègumas, vikrumas.

\section{IVADAS}

$\mathrm{J}$ aunų žaidèjų patekimas į didelio meistriškumo komandas priklauso nuo daugelio veiksnių. Vienas iš esminių rodiklių — jų fizinis išsivystymas ir fizinis pajègumas. Merginų krepšinis Lietuvoje nèra toks masiškas kaip vaikinu ir ju pasiektu pergalių tarptautinèse varžybose skaičius yra mažesnis. Krepšininkių meistriškumo raidą lemia tikslinga atranka, kvalifikuotas ugdymas, treniruotumo kaitos kontrole ir veiksminga rengimo korekcija (Krause et al., 1999; Goldstein, 2002; Karoblis, 2005; Бондарчюк, 2005).

Daugeli metu Lietuvos olimpinis sporto centras (LOSC) rengia jaunas krepšininkes, kurios nuolat stebimos mokslininkų ir medikų, tačiau apie didelio meistriškumo komandas ir netgi Lietuvos nacionalinès rinktinès žaidèjas mokslinès infor- 
macijos turime nedaug. Akivaizdu, kad jaunų ir suaugusiu sportininkiu kai kurie fizinio išsivystymo, fizinio ir funkcinio pajègumo rodikliai skiriasi (Bompa, 1999; Joy, Macintyre, 2001; Stasiulis, Zachovajevas, 2007). Tačiau kuriuo laikotarpiu ir kokių rodikliu skirtumas yra pats ryškiausias, tyrinèta nepakankamai.

Lieka aktualu ištirti, kaip skiriasi ne tik somatiniai fizinio išsivystymo rodikliai, bet ir žaideju fiziniai, funkciniai gebejjimai. Tai svarbu žinoti pereinant iš merginu i moterų komandas. Spręsdami šia problemą tyrème jaunas LOSC krepšininkes ir pajėgiausios Lietuvos moterų krepšinio komandos Vilniaus TEO žaidèjas.

Tyrimo tikslas - ištirti 16 metu ir didelio meistriškumo krepšininkių fizinįi išsivystymą, fizini, funkcini pajègumą, atlikti lyginamają analizę.

\section{TYRIMO ORGANIZAVIMAS IR METODAI}

Tirtos jaunos (16 metų amžiaus) krepšininkès $(\mathrm{n}=13)$ ir moteru Eurolygos varžybų žaidèjos $(\mathrm{n}=15)$. Krepšininkiu fizinis išsivystymas tirtas atliekant antropometrinius, fiziometrinius matavimus ir naudojant standartinę metodiką (Skernevičius ir kt., 2004). Tyrimu nustatyta:

- Ūgis.

- Kūno masè, kūno masès indeksas (KMI).

- Plaštakų statinès jègos rodikliai.

- Gyvybinis plaučiu tūris (GPT).

- Riebalu ir raumenu masé ir jų indeksas (RRMI) (Juocevičius, Guobys, 1985).

Fizinès galios tirtos nustačius:

- Vienkartini raumenų susitraukimo galingumą (VRSG) (Bosco et al., 1983).

- Anaerobini alaktatini raumenų galingumą (AARG) (Margaria et al., 1966).

- 30 s darbo veloergometru - mišru anaerobini alaktatini-glikolitini raumenu galinguma (AAGRG) (Dotan, Bar-Or, 1983).

Vikrumas tirtas „Šešiakampio“ testu - matuotas laikas, sugaištas šuoliuojant tris ratus už visuz stačiakampio kraštinių (Brittenham, 1998).

Psichomotorinès funkcijos tirtos nustačius psichomotorinès reakcijos laiką (PRL) ir judesiu dažni (JD) per $10 \mathrm{~s}$.

Kraujotakos ir kvèpavimo sistemų funkcinis pajègumas vertintas pagal Rufjè indeksą (Шepep, 1973), taip pat matuotas pulso dažnis ramybès būsenoje, ortostazès metu, reaguojant ị standartini fizinị krūvị (atliekant 30 pritūpimų per $45 \mathrm{~s}$ ) ir atsigaunant per $1 \mathrm{~min}$.
Tyrimo rezultatai apdoroti matematinès statistikos metodais: apskaičiuotas aritmetinis vidurkis $(\overline{\mathrm{X}})$, reprezentacinė paklaida $(\mathrm{S} \overline{\mathrm{x}})$, standartinis nuokrypis (S). Taip pat pateikti didžiausias ir mažiausias rodikliai. Apskaičiuotas aritmetiniu vidurkiu skirtumo patikimumas taikant dispersinès analizès metodą, nustačius $F$ kriterijų. Norint vaizdžiai palyginti atskirų žaidèjų ir grupių i̇vairius rodiklius, duomenys standartizuoti ir sudaryti normalizuotu rodiklių profiliai (Gonestas, Strielčiūnas, 2003).

\section{REZULTATAI}

Ištyrę abiejų grupių sportininkes nustatème, kad jų somatiniu fizinio išsivystymo rodiklių vidurkiai - ūgis ir kūno masė patikimai nesiskyrè. Tačiau 1 lentelejje pateikti duomenys rodo, kad jaunų krepšininkių riebalu masè buvo statistiškai patikimai didesnè $(p<0,001)$. Abiejų grupių GPT rodikliai patikimai nesiskyrè. Šioje lentelëje taip pat pateikiama ir plaštakų statinè jèga. Suaugusiu žaidèjų dešinès plaštakos jèga vidutiniškai siekè $4,73 \mathrm{~kg}(\mathrm{p}<0,04)$, kairès - 4,29 kg $(\mathrm{p}<0,007)$ didesnè negu jaunú.

Fizinio pajègumo tyrimas parode ( 2 lent.), kad žaidžiant krepšini ypač svarbūs šuolio aukščio rodikliai: didelio meistriškumo žaidejjų — vidutiniškai 44,6 cm, jaunu — tik $37,54 \mathrm{~cm}(\mathrm{p}<0,001)$. Pasispyrimo greičio rodikliai šuolio metu tarp grupių skyrèsi mažai $(p>0,05)$. VRSG santykinis rodiklis suaugusių žaidejjų buvo didesnis negu jaunu $(\mathrm{p}<0,03)$. Ypač didelis AARG rodiklių skirtumas. Vyresnių žaidèjų santykinis AARG $-1,31 \mathrm{~W} / \mathrm{kg}$ didesnis negu jaunu $(\mathrm{p}<0,005)$.

Mišrus anaerobinis alaktatinis-glikolitinis raumenu galingumas atliekant $30 \mathrm{~s}$ darbą ergometru buvo didesnis vyresnès grupès sportininkiu $(\mathrm{p}<0,01)$.

Judesių dažnis per $10 \mathrm{~s}$ didelio meistriškumo krepšininkiu yra statistiškai patikimai didesnis $(\mathrm{p}<0,002)$ negu jaunų žaidèjų, tačiau psichomotorinès reakcijos laikas tarp grupių vidurkiu iš esmès nesiskyrè.

Abiejų grupių vikrumo rodiklių vidurkiai statistiškai nesiskyrè $(\mathrm{p}>0,05)$.

Tiriant kraujotakos ir kvejpavimo sistemu funkcini pajėgumą matyti (1 pav.), kad pulso dažnis ramybès būsenoje didelio meistriškumo krepšininkių vidutiniškai sieke $56,27 \mathrm{tv}$. / min, jaunimo komandos žaideju $-69,62 \mathrm{tv}$. / min, skirtumo tarp grupių vidurkiu patikimumas $-\mathrm{p}<0,01$. Pulso reakcijos ị standartini fizini krūvị rodikliai abieju 
1 lentelè. Suaugusių ir jaunų krepšininkių fizinio išsivystymo duomenys

\begin{tabular}{|c|c|c|c|c|c|c|c|c|c|c|}
\hline \multirow[b]{2}{*}{ Tiriamosios } & \multirow[b]{2}{*}{ Rodikliai } & \multirow[b]{2}{*}{$\overline{\text { Ugis, }} \mathbf{c m}$} & \multirow{2}{*}{$\begin{array}{l}\text { Kūno } \\
\text { masé, } \\
\text { kg }\end{array}$} & \multirow[b]{2}{*}{$\begin{array}{l}\mathrm{KMI}, \\
\mathrm{kg} / \mathrm{m}^{2}\end{array}$} & \multicolumn{2}{|c|}{ Plaštakų jèga, kg } & \multirow[b]{2}{*}{ GPT, I } & \multirow[b]{2}{*}{$\begin{array}{l}\text { Riebalų } \\
\text { masė, kg }\end{array}$} & \multirow[b]{2}{*}{$\begin{array}{c}\text { Raumenų } \\
\text { masė, kg }\end{array}$} & \multirow[b]{2}{*}{ RRMI } \\
\hline & & & & & D & $\mathbf{K}$ & & & & \\
\hline \multirow{5}{*}{$\begin{array}{l}\text { Suaugusios krep- } \\
\text { šininkès }\end{array}$} & $\overline{\mathrm{X}}$ & 182,53 & 73,07 & 21,91 & 40,73 & 39,67 & 4,51 & 9,31 & 39,59 & 4,46 \\
\hline & $\mathrm{S} \overline{\mathrm{x}}$ & 1,68 & 2,26 & 0,45 & 1,61 & 1,23 & 0,12 & 0,64 & 1,30 & 0,27 \\
\hline & $\mathrm{S}$ & 6,50 & 8,75 & 1,73 & 6,24 & 4,78 & 0,47 & 2,49 & 5,04 & 1,04 \\
\hline & Min & 170,00 & 60,50 & 18,90 & 25,00 & 28,00 & 3,80 & 5,20 & 30,80 & 3,09 \\
\hline & Max & 194,00 & 86,00 & 24,60 & 46,00 & 45,00 & 5,40 & 14,10 & 47,40 & 6,98 \\
\hline \multirow{5}{*}{$\begin{array}{l}\text { Jaunos krepšinin- } \\
\text { kės }\end{array}$} & $\bar{X}$ & 181,31 & 71,35 & 21,52 & 36,00 & 34,38 & 4,38 & 13,38 & 37,63 & 3,10 \\
\hline & $\mathrm{S} \overline{\mathrm{x}}$ & 2,53 & 2,51 & 0,45 & 1,41 & 1,32 & 0,11 & 0,68 & 1,42 & 0,30 \\
\hline & $\mathrm{S}$ & 9,10 & 9,06 & 1,64 & 5,08 & 4,75 & 0,41 & 2,47 & 5,11 & 1,07 \\
\hline & Min & 165,50 & 56,00 & 18,00 & 28,00 & 28,00 & 3,80 & 7,40 & 29,20 & 2,27 \\
\hline & Max & 195,00 & 91,50 & 24,40 & 47,00 & 45,00 & 5,20 & 16,30 & 47,40 & 6,04 \\
\hline \multirow{2}{*}{ Patikimumas } & $\mathbf{F}$ & 0,171 & 0,261 & 0,359 & 4,745 & $\mathbf{8 , 5 5 7}$ & 0,524 & 18,822 & 1,042 & 11,669 \\
\hline & $\mathbf{p}$ & 0,682 & 0,614 & 0,554 & $\mathbf{0 , 0 3 9}$ & $\mathbf{0 , 0 0 7}$ & 0,476 & 0,001 & $\mathbf{0 , 3 1 7}$ & 0,002 \\
\hline
\end{tabular}

2 lentelè. Suaugusių ir jaunų krepšininkių fizinio bei funkcinio pajègumo tyrimų duomenys

\begin{tabular}{|c|c|c|c|c|c|c|c|c|c|c|c|c|}
\hline \multirow{2}{*}{ Tiriamosios } & \multirow{2}{*}{ Rodikliai } & \multirow{2}{*}{$\begin{array}{l}\text { Šuolio } \\
\text { aukš- } \\
\text { tis, cm }\end{array}$} & \multirow{2}{*}{$\begin{array}{c}\text { Atsisp. } \\
\text { laikas, } \\
\text { ms }\end{array}$} & \multicolumn{2}{|c|}{ VRSG } & \multicolumn{2}{|c|}{ AARG } & \multirow{2}{*}{$\begin{array}{c}\text { AAGRG } \\
\text { W } \\
30 \text { s vid. }\end{array}$} & \multirow{2}{*}{$\begin{array}{l}\text { PRL, } \\
\text { ms }\end{array}$} & \multirow{2}{*}{$\begin{array}{c}\text { J. d., } \\
\text { k. / } 10 \text { s }\end{array}$} & \multirow{2}{*}{$\begin{array}{l}\text { Vikrumas, } \\
18 \text { šuol. / s }\end{array}$} & \multirow{2}{*}{ RI } \\
\hline & & & & W / kg & $\mathbf{W}$ & W / kg & $\mathbf{W}$ & & & & & \\
\hline \multirow{5}{*}{$\begin{array}{l}\text { Suaugusios } \\
\text { krepšininkės }\end{array}$} & $\bar{x}$ & 44,60 & 202,80 & 21,86 & 1601,07 & 14,77 & 1080,33 & 526,40 & 178,87 & 82,47 & 13,16 & 5,41 \\
\hline & $\mathrm{S} \overline{\mathrm{X}}$ & 1,28 & 6,96 & 0,93 & 90,31 & 0,31 & 42,22 & 13,75 & 2,82 & 2,13 & 0,44 & 0,97 \\
\hline & $\mathrm{S}$ & 4,94 & 26,95 & 3,61 & 349,75 & 1,21 & 163,54 & 53,24 & 10,91 & 8,25 & 1,69 & 3,75 \\
\hline & Min & 35,00 & 161,00 & 16,86 & 1064,00 & 12,90 & 900,00 & 407,00 & 157,00 & 72,00 & 11,06 & 0,00 \\
\hline & Max & 55,00 & 253,00 & 28,24 & 2428,00 & 16,60 & 1374,00 & 628,00 & 195,00 & 96,00 & 17,44 & 11,60 \\
\hline \multirow{5}{*}{$\begin{array}{l}\text { Jaunos } \\
\text { krepšininkès }\end{array}$} & $\overline{\mathrm{X}}$ & 37,54 & 197,69 & 18,91 & 1341,69 & 13,46 & 955,08 & 460,38 & 163,22 & 73,31 & 13,04 & 7,97 \\
\hline & $\mathrm{S} \overline{\mathrm{X}}$ & 1,36 & 7,41 & 0,88 & 68,78 & 0,29 & 26,14 & 21,41 & 13,98 & 1,48 & 0,24 & 1,00 \\
\hline & $\mathrm{S}$ & 4,91 & 26,73 & 3,17 & 247,99 & 1,03 & 94,24 & 77,19 & 50,39 & 5,33 & 0,86 & 3,60 \\
\hline & Min & 24,00 & 163,00 & 10,59 & 784,00 & 11,27 & 789,00 & 292,00 & 1,81 & 65,00 & 11,16 & 3,60 \\
\hline & Max & 44,00 & 268,00 & 21,86 & 1649,00 & 14,90 & 1148,00 & 565,00 & 191,00 & 87,00 & 14,19 & 16,00 \\
\hline \multirow{2}{*}{ Patikimumas } & $\mathbf{F}$ & 14,313 & 0,252 & 5,203 & 4,971 & 9,352 & 5,906 & 7,098 & 1,380 & 11,752 & 0,053 & 3,356 \\
\hline & $\mathbf{P}$ & 0,001 & 0,620 & 0,031 & 0,035 & 0,005 & 0,022 & 0,013 & 0,251 & 0,002 & 0,820 & 0,078 \\
\hline
\end{tabular}

grupiu taip pat buvo skirtingi $(\mathrm{p}<0,02)$. Vyresniu žaidejuu pulsas padidèjo iki 133,47 tv. / min, jaunesnių - iki 145,08 tv. / min. Po krūvio vyresniu žaidejju pulso dažnis grižo ì pradini lygi greičiau negu jaunesnių $(\mathrm{p}<0,05)$. Dauguma abiejų grupių širdies ritmo rodiklių buvo skirtingi, Rufjè indeksas didelio meistriškumo žaideju $-5,4$, jaunu 7,9 , tačiau esant didelei rodiklių sklaidai statistiškai patikimo skirtumo neužfiksuota $(p>0,05)$.

\section{REZULTATŲ APTARIMAS}

Daugelis autoriu yra tyrę ne tik žmogaus augimo, brendimo chronologiją, bet ir adaptacijos prie fizinių krūvių ypatumus. Krepšinio žaidimo fiziniai krūviai yra specifiniai. Fizinio krūvio ir amžiaus poveikis dažnai yra susijęs su morfologiniais ir fiziologiniais rodiklių pokyčiais (Malina, Bouchard, 1991). Nustatyta, kad 16 metu amžiaus krepšininkès savo ūgiu ir kūno mase jau prilygsta didelio meistriškumo komandos žaidejoms, tačiau smarkiai skiriasi plaštakų statine jèga. Tyrimas rodo, kad šis rodiklis didejant meistriškumui sparčiai kinta. Riebalų masės dydis yra svarbus daugeliui žmogaus gyvybinių procesų. Per maža riebalų masė gali trukdyti normaliam vystymuisi, per didelè - apsunkina fizinę veiklą (Dadelienè, 2008). Tirtos suaugusios žaidèjos skyrèsi nuo jaunu mažesne riebalų mase ir didesniu raumenų kiekiu, todèl didelio meistriškumo krepšininkiu 

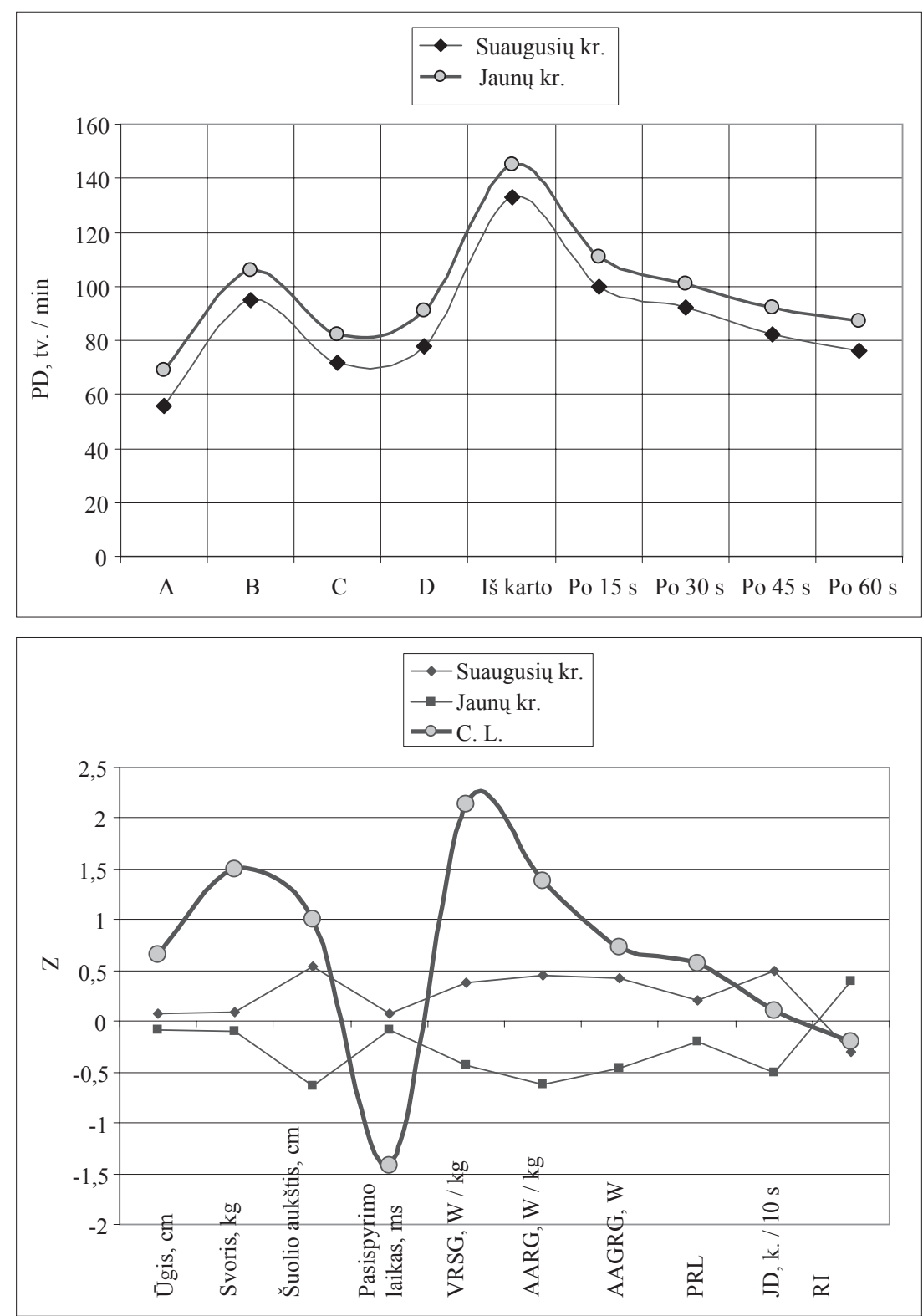

1 pav. Suaugusių ir jaunų krepšininkių pulso dažnio rodikliai

Pastaba. A - gulint; B - tik atsistojus, kai labiausiai padažnèja; $\mathrm{C}$ — stovint, kai labiausiai suretèja; D — kai stabilizuojasi, iš karto po standartinio fizinio krūvio ir per $1 \mathrm{~min}$ atsigavimo laikotarpi.

2 pav. Suaugusių, jaunu krepšininkių ir rezultatyviausios Eurolygos žaidėjos C. L. standartizuotų rodiklių profiliai
RRMI yra didelis, jaunų — vidutinis (Skernevičius ir kt., 2004).

Vienas iš svarbesnių krepšinio žaidèjų parengtumo rodiklių yra šuolio aukštis. Jaunų krepšininkių šis rodiklis net $7,1 \mathrm{~cm}$ mažesnis negu suaugusių. Aukščiau pašokant galima turèti didesni pranašumą žaidimo metu, todèl tyrimo rezultatai leidžia teigti, kad jaunos krepšininkès turètų daugiau dèmesio skirti šuolio aukščio didinimui.

Labai informatyvus yra VRSG tyrimas. Jis parodo greitai susitraukiančių skaidulu procentini skaičiu (Bosco et al., 1983), taip pat sportininkiu galimybę ne tik aukštai pašokti bet ir greitai pasispirti. Manome, kad didelio meistriškumo komandos žaidejjų vidutinis VRSG rodiklis 21,86 W / kg yra nepakankamas, o jaunų krepšininkių (18,91 W/ kg) yra mažas (Stonkus, 2002). Tai leidžia daryti prielaida, kad šios ypatybės ugdymui, ypač jaunimo komandose, dèmesio skiriama nepakankamai.

Kaip vienas pagrindinių žaidèjų fizinio pajègumo rodikliu yra anaerobinis alaktatinis raumenų galingumas. Greitumą treniruojančių moterų šis rodiklis gali siekti nuo 16 iki 20 W / kg (Skernevičius ir kt., 2004). Nors žaidžiant krepšini vyrauja įvairios greitumo poreiškio formos, moteru AARG siekè tik 14,77 W / kg, merginų $1,31 \mathrm{~W} / \mathrm{kg}(\mathrm{p}<0,005)$ mažesnis.

Mišrus AAGRG rodiklis žaidžiant krepšini $30 \mathrm{~s}$ taip pat informatyvus. Krepšinio žaidimo taisyklès leidžia kontroliuoti kamuoli 24 sekundes. Per tą laiką žaidèjai atlieka kelis greitejjimus, kartotinius šuolius, bejgimus keičiant krypti ir pan. Tokiai žaidimo veiklai svarbūs geri AAGRG rodikliai. Ištyrę abiejų grupių krepšininkes matome, kad jaunos žaidèjos smarkiai atsilieka nuo suaugusių. 
Suaugusių žaidèjų daug geresni judesių dažnio rodikliai, parodantys CNS paslankumą, o abieju grupiu psichomotorinès reakcijos laiko vidurkiai patikimai nesiskyre ir buvo vidutinio lygio. Nors kai kurie autoriai teigia, kad žaidimu sportas veikia PRL, tačiau kiti skirtumų tarp didelio meistriškumo sportininkų ir jaunų nesportuojančių žmonių nepastebejjo (Skernevičius ir kt., 2004; Dadelienè, 2008).

Sportininkų organizmui adaptuojantis prie fizinių krūvių didèja širdies ertmè ir sistolinis tūris, o pulsas ramybès būsenoje ir po fizinio krūvio darosi retesnis (Astrand, Rodahl, 1986; Ehsani et al., 1991). Nustatę Rufjè indeksą galime teigti, kad abiejų grupių žaidejų kraujotakos ir kvėpavimo sistemos funkcinis pajègumas yra didelis. Tačiau iš 1 pav. matyti, kad didelio meistriškumo krepšininkių pulso dažnis ramybès būsenoje yra retesnis, standartinio fizinio krūvio metu - mažesnis, o atsigaunant — retesnis.

Standartizavus abiejų grupių ir naudingiausios Eurolygos varžybų krepšininkès C. L. rodiklius ir sudarius ju profilius matyti ( 2 pav.), kad grupiu standartizuoti rodikliai skiriasi. Ypač išryškejjo didelis žaidejjos C. L. trumpo raumenų darbo galingumo rodiklių skirtumas. Jos šuolio aukščio, pasispyrimo greičio ir VRSG rodikliai daug geresni negu visu tiriamujuc. AARG yra taip pat didesnis ir net per 1,38 standartinius nuokrypius (S) yra nutolęs nuo abiejų grupių vidurkio. Šis tyrimas leidžia manyti, kad geri fizinio pajègumo rodikliai lemia puikius asmeninius rezultatyvumo rodiklius varžybose. Dideli VRSG ir AARG rodikliai, suderinti su žaidimo technika, suteikia pranašumo prieš varžovus tiek puolant, tiek ginantis.

\section{IŠVADOS}

1. 16 metų krepšininkès savo ūgiu ir kūno mase nesiskiria nuo didelio meistriškumo komandos žaidejjų. Tačiau jos atsilieka plaštaku jèga, ju kūno riebalų masė didesnè.

2. Santykinis VRSG rodiklis suaugusių žaidejjų yra kur kas didesnis negu jaunų krepšininkių. Taip pat AARG ir AAGRG rodikliai vyresniuc buvo geresni nei jaunų krepšininkių. Abiejų grupių vikrumo rodikliai skyressi nepatikimai.

3. Psichomotorinès reakcijos laiko rodikliai tarp grupių patikimai nesiskyrè, tačiau judesių dažnis didelio meistriškumo žaidèjų buvo didesnis.

4. Abiejų grupių žaidèjų kraujotakos ir kvėpavimo sistemos funkciniai rodikliai buvo geri, jaunu krepšininkių Rufjè indeksas patikimai nesiskyrè nuo suaugusių žaidejjų to paties rodiklio.

5. Rezultatyviausia didelio meistriškumo komandos žaideja yra geresnio fizinio ir funkcinio pajègumo, jos VRSG ir AARG rodikliai ypač geri.

\section{LITERATŪRA}

Astrand, P.-O., Rodahl, K. (1986). Textbook of Work Physiology. $2^{\text {nd }}$ edition. NY: McGaw-Hill.

Bompa, T. O. (1999). Theory and Methodology of Training. USA: Human Kinetics.

Bosco, C., Komii, P., Tihanyi, J., Fekete, C., Apor, P. (1983). Mechanical power test and fiber composition of human leg extensor muscles. European Journal of Applied Physiology, 53, 129-135.

Brittenham, G. (1998). Complete Conditioning for Basketball. Human kinetics. P. $45-49$.

Dadelienè, R. (2008). Kineziologija. Vilnius: LSIC. P. $122-128$.

Dotan, R., Bar-Or, O. (1983). Load optimization for Wingate anaerobic test. European Journal of Applied Physiology, 51,409-417.

Ehsani, A. A., Ogawa, T., Miller, T. R., Spina, R. J., Jilka, S. M. (1991). Exercise training improves left ventricular systolic function in older man. Circulation, 83, 96-103.

Goldstein, S. (2002). The Basketball Coach's Bible. USA: Golden Aura Publishing.

Gonestas, E., Strielčiūnas, R. (2003). Taikomoji statistika. Kaunas: LKKA.

Joy, E. A., Macintyre, J. G. (2001). Women in Sports. Team physician's handbook (3rd ed.). 77-95.
Juocevičius, A., Guobys, H. (1985). Reumatinèmis ligomis sergančiuju fizinio pajégumo ir reabilitacijos potencialo kompleksinis ìvertinimas. Vilnius. P. 16.

Karoblis, P. (2005). Sportinio rengimo teorija ir didaktika. Vilnius: Infoastras.

Krause, J. V., Meyer, D., Meyer, J. (1999). Basketball Skills and Drills. 2nd edition. Human Kinetics.

Malina, R. M., Bouchard, C. (1991). Growth, Maturation, and Physical Activity. Champaign, Illinois: Human Kinetics.

Margaria, R., Aghemo, P., Rovelli, E. (1966). Measurement of muscular power (anaerobic) in man. European Journal of Applied Physiology, 21, 1662-1664.

Skernevičius, J., Raslanas, A., Dadeliene, R. (2004). Sporto mokslo tyrimu metodologija. Vilnius: Lietuvos sporto informacijos centras.

Stasiulis, A., Zachovajevas, P. (2007). Fizinis rengimas atsižvelgiant $\mathfrak{i}$ organizmo sandarą ir funkcini gebejjimą prisitaikyti. Trenerio knyga. Fizinis rengimas. Kaunas. P. $181-228$.

Stonkus, S. (2002). Krepšinio testai. Kaunas: LKKA. P. 89.

Бондарчюк, А. (2005). Периодизаичя спортивной тренировки. Киев: Олимпийская литература.

Шерер, Ж. (1973). Физиология труда. Эргономия. Ред. 
проф. 3. Н. Золина. Москва: Медицина. С. 29-39.

\title{
COMPARATIVE ANALYSIS OF PHYSICAL DEVELOPMENT LEVEL, PHYSICAL CAPACITY AND FUNCTIONAL INDICES OF FEMALE BASKETBALL PLAYERS OF DIFFERENT PERFORMANCE LEVELS AND DIFFERENT AGE
}

\author{
Rūtenis Paulauskas, Juozas Skernevičius, Rasa Paulauskienė \\ Vilnius Pedagogical University, Vilnius, Lithuania
}

\begin{abstract}
The aim of the research was to evaluate physical development, physical and functional capacity of women basketball players aged 16 years and women basketball players of high performance level and to carry out a comparative analysis of their indexes.

Height, body mass, body mass index (BMI), static hand power, vital lung capacity (VLC), fat and muscle mass index (FMMI) were measured in this research. Single muscular contraction power (SMCP), anaerobic alactic muscular power (AAMP) and mixed anaerobic alactic glycolytic muscle power (AAGMP) with applied $30 \mathrm{~s}$ veloergometer test were established aiming to perform the analysis of physical and functional power. Agility Hexagon test was performed too. The duration of psychomotoric reaction (DPR) and movement frequency (MF) in $10 \mathrm{~s}$ were established aiming to analyse psychomotoric functions. Functional capacity of blood circulation and respiratory systems was estimated by the Roufier index. The results of the research were processed employing the methods of mathematical statistics: arithmetic average $(\overline{\mathrm{X}})$, representative bias $(S \bar{x})$ and statistic deviation (S) were calculated. Max and min indexes were also represented. The method of dispersive analysis (ANOVA), after establishing F parameter, was used to evaluate reliability of differences between indexes. The data was standardized and profiles of normalized indexes were formed for various indexes of individual players and groups for further profile comparison.

The research demonstrated that women basketball players aged 16 years did not already make a contrast with high performance team players as to the indexes of height and body mass. But they lagged behind with their hand power and distinguished themselves by greater body fat mass.

It was established that relative index of SMCP of high performance players was considerably higher than of younger players. However, there was no statistically reliable difference between the agility indices of both groups.

The duration of psychomotoric reaction did not give any reliable difference between these two groups, but movement frequency of high performance players was higher.

The players of both groups had good functional indexes of blood circulation and respiratory systems, and Roufier index of younger athletes did not make a contrast with the one of high performance players. The highest-scoring player of high performance had remarkably better physical and functional capacity and had especially good SMCP and AAMP indexes.
\end{abstract} agility.

Keywords: women basketball, physical capacity, power, muscle mass, strength, functional capacity,

Gauta 2009 m. sausio 19 d.

Received on January 19, 2009

Priimta 2009 m. gegužès 6 d.

Accepted on May 6, 2009
Rūtenis Paulauskas

Vilniaus pedagoginis universitetas

(Vilnius Pedagogical University)

Studentų g. 39, LT-06316 Vilnius

Lietuva (Lithuania)

Tel+370 69839079

E-mail rutenis2006@yahoo.com 